\title{
Masif rotator manşet yırtıkları
}

\author{
Massive rotator cuff tears
}

\author{
Mahmut Nedim Doral1,2, Burkay Utku ${ }^{1}$, Çağlar Yılgör ${ }^{2}$ \\ ${ }^{1}$ Hacettepe Üniversitesi Tıp Fakültesi, Spor Hekimliği Anabilim Dalı, Ankara \\ ${ }^{2}$ Hacettepe Üniversitesi Tıp Fakültesi, Ortopedi ve Travmatoloji Anabilim Dalı, Ankara
}

\begin{abstract}
Masif rotator manşet yırtıkları işlev ve işgücü kaybına neden olabilir. Cerrahi dışı tedavilere dirençli olan masif rotator manşet yırtıkları, en sık görülen ortopedik sorunlar arasındadır. Masif yırtık kavramı farklı şekillerde tanımlanmıştır. Rotator manşet ve kapsül, birbirlerine karışarak sonlandıkları için, tam kat yırtıklarda beraber ayrılabilirler. Manşet yırtıklarında en çok supraspinatus kasının tendonu yırtılır. Bunun nedeni, Neer'e göre, kendisinin tanımladığı kritik zondur. Masif rotator manşet yırtıkları etiyolojisinde akromiyon tipleri ve sigara içimi de önemli bir rol oynamaktadır. Yırtık tanısı, görüntüleme yöntemleri ile konulmaktadır. En çok kullanılan iki yöntem MRG ve USG'dir. Cerrahi olarak çok geniş bir yelpazede tedavi seçenekleri bulunup her hasta özelinde uygun tedavi yöntemi seçilmelidir.
\end{abstract}

Anahtar sözcülkler: manşon, rotator; tendonlar; akromiyon
M asif rotator manşet yırtıkları (RKY), ağrı ve işlev bozuklukları oluşturabilen en sık görülen ortopedik sorunlardan birisidir. Rotator manşet, anatomik olarak subscapularis, supraspinatus, infraspinatus ve teres minör kaslarının kirişleri tarafından oluşturulmaktadır (Şekil 1). Bu manşet ilerleyen yaşla birlikte dejenerasyona uğramakta ve bu dejenerasyon da RKY'ye neden olmaktadır. Genellikle küçük yırtıklar daha yaşlı bireylerde asemptomatik olarak seyrederken, daha büyük veya tam kat yırtıklar daha genç bireylerde semptomatik olarak seyretmektedir. Masif yırtıklar güçsüzlüğe, işgücü kaybına, kronik ağrı ve ciddi işlev bozukluğuna neden olabilirler. Genellikle cerrahi dışı tedavilere dirençlidirler.

\section{TANIM}

Masif yırtığın tanımlanmasında ortak bir görüş bulunmamaktadır. Masif yırtık terimi özellikle tamiri zor
Massive rotator cuff tears can cause loss of function and workforce. It is among the most often seen orthopedic problems and may be very resistant to non-operative treatment. The concept of massive tear has been described in various ways. As the rotator cuff and the capsule fuse at their insertion, they may cleave together in full-thickness tears. The most commonly torn cuff element is the supraspinatus tendon. According to Neer, that's because of the critical zone defined by him. Acromion types and smoking also plays an important role in the etiology of rotator cuff tears. Imaging methods are widely used in the diagnosis of the tears. MR and US imaging are the more commonly used two methods. There is a wide spectrum of surgical options and the treatment should be personalized.

Key words: rotator cuff; tendons; acromion olan yırtıklar için kullanılmaktadır ve bu yırtıklar değişken bir prognoza sahiptir (Şekil 2).

Cofield, ${ }^{[1]}$ masif yırtığı çapı $5 \mathrm{~cm}$ 'den büyük yırtıklar şeklinde tanımlarken, Gerber, ${ }^{[2]}$ masif yırtık tanımını iki veya daha fazla tendonun yapışma yerinden tam olarak ayrılması şeklinde yapmaktadır. Tauro ${ }^{[3]}$, yırtığın anteroposterior ve mediolateral boyutlarının oranını ortaya koyduğu indeksi kullanmaktadır. Burkhart ${ }^{[4]}$ ise, yırtık paternine ve yırtık kenarlarının hareketliliğine göre bir sınıflandırma sistemi geliştirmiştir. Hilal şeklindeki yırtıklar klasik olandır ve medialden laterale olan hareketliliği iyidir. Minimal gerginlik ile tamir edilebilir. U şeklindeki yırtıklar ise mediale doğru uzanım gösterirler. Yırtığın tepesi glenoid kenara çok yakındır. Bu yırtık paterninde tendon doğrudan kemiğe dikilmeden önce, gerginliği azaltabilmek için uç uca 'margin convergence' dikişi gerekmektedir. ${ }^{[5]}$ Warner ve ark. ${ }^{[6]}$ ise, yırtığın yerleşimine göre sınıflama yaparak, çoğu

- Illetişim adresi: Prof. Dr. Mahmut Nedim Doral, Büklüm Sk. No:72 Kavaklıdere, Ankara

Tel: 0312 - 4663838 e-posta: mndoral@gmail.com

- Geliș tarihi: 22 Temmuz 2013 Kabul tarihi: 25 Ekim 2013 


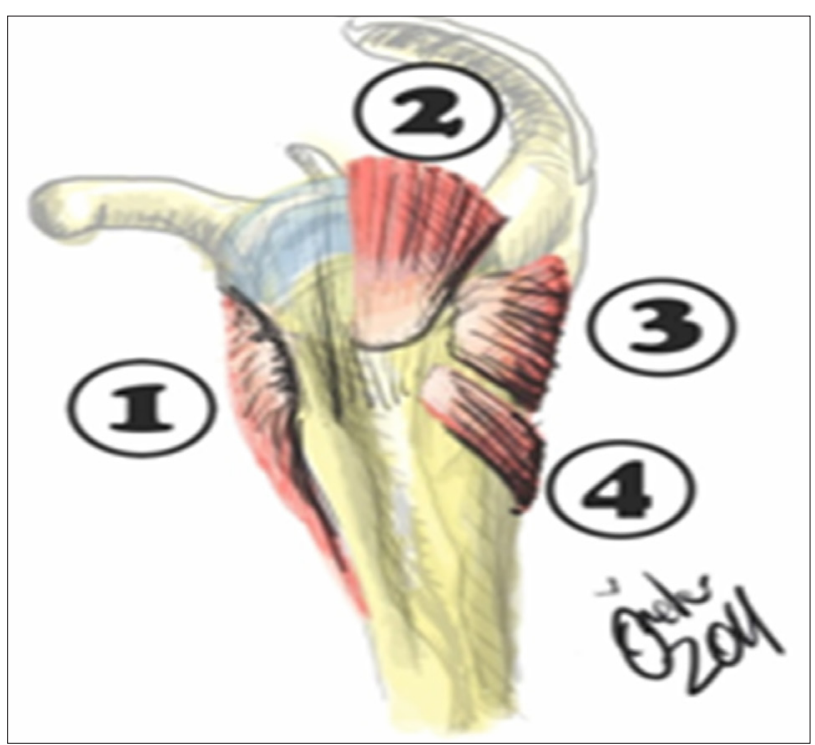

Şekil 1. Rotator manşetin anatomik görünümü. (1- M.Subscapularis, 2- M.Supraspinatus, 3- M.Infraspinatus, 4- M.Teres Minor).

yırtığın postero-superior ve antero-superior olmak üzere iki ayrı anatomik paterne uyduğunu öne sürmüşlerdir. Yırtıkların çoğu postero-superior olup supraspinatus ve infraspinatusu içerirler ve teres minör yırtıkları da bu paterne eşlik edebilir. Aksine antero-superior yırtık ise, supraspinatus ve subskapularisi içerir ve buna biseps tendon yırtıkları eşlik edebilir. ${ }^{[6]}$

Rotator manşet ve kapsül birbirlerine karışarak insersiyolarına ulaşırlar. Tam kat yırtıkta hem kapsül hem de tendon yerlerinden ayrilır. Tendon retrakte olurken, kapsül kontrakte olur. Oluşan ilk yırtık iğne deliği şeklinde iken, ilerledikçe klasik yarım ay şeklini alır. Tam kat yırtıklar küçük $(<1 \mathrm{~cm})$, orta $(1-3 \mathrm{~cm})$, büyük $(3-5$ $\mathrm{cm})$ ve masif $(>5 \mathrm{~cm})$ olarak sınıflandırılırlar. Kısmi yırtıklar genellikle tendonun eklem yüzünde gelişirler. ${ }^{[7]}$

Gerber ve ark., ${ }^{[2]}$ hastaların vücut yapı farklılıkları ve yırtığın boyutunu ölçerken kullanılan farklı metodlar nedeniyle, humerusun tuberkulumlarından ayrılan tendon miktarına bakarak yırtık büyüklüğünü tanımlamanın daha uygun olacağını öne sürmüşler$\operatorname{dir}^{[2]}$ ve en az iki tendon bütün olarak yapışma yerlerinden ayrılmışsa, RKY'yi masif tendon yırtığı olarak adlandırmaktadırlar.

Yine de bütün bu sınıflandırma sistemleri, hastanın vücut yapısına, ölçüm tekniğine, ölçüm esnasında kolun pozisyonuna göre değişkenlik gösterebilmektedir. Literatürdeki çalışma sonuçlarına göre masif yırtık prevalansı tüm RKY içinde \%10-40 arası değişen bir orana sahiptir. ${ }^{[5]}$ Masif rotator manşet yırtıkları ayrıca, akut, kronik üzerine akut ve kronik olarak da sınıflandırılabilir. ${ }^{[8]}$

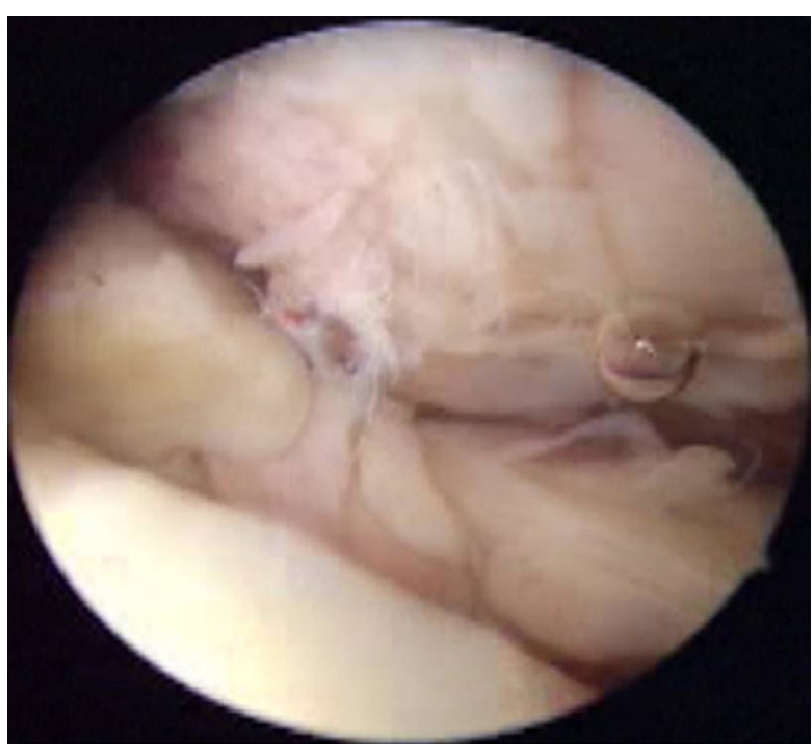

Şekil 2. Artoskopik masif rotator manşet yırtığının görüntüsü.

\section{PATOFIZYOLOJi}

Codman, ${ }^{[1]}$ yaptığı klinik çalışmalar sonucunda, 1934 yılında supraspinatus kasının tendonunun en çok yırtılan tendon olduğu ortaya koymuştur. Neer, ${ }^{[9]}$ bunun nedeninin supraspinatus tendon yapışma yeri yakınındaki kritik zon olduğunu öne sürmüştür. Kritik zon, damarlanmanın az olduğu; humerusun büyük tüberkülündeki yapışma yerine yaklaşık bir santimetre uzakta olan bölgedir.

Neer, kadavralar üzerinde yaptığı çalışma sonucunda akromiyonun şekil ve eğim farklılıklarını ve korakoakromiyal bağın akromiyal kısmında ve akromiyonun 1/3'lük ön kısmının alt yüzeyinde osteofit oluşumlarını tariflemiş ve bu anatomik varyasyon ve dejeneratif değişikliklerin kritik zon ve hemen altında bulunan biseps tendonunun maruz kaldıkları travmanın kaynağı olduğunu belirtmiştir. ${ }^{[9]}$ Neer, çalışmasında kolun günlük hayatta en çok bulunduğu pozisyon olan iç rotasyon esnasında akromion altından geçen anatomik yapıların daha da öne geldiğini, dış rotasyon ile de supraspinatus tendonunun yapıştığı fasetin, akromiyonun 1/3 ön kısmının lateraline düştügüunü, bu yüzden de iç rotasyondaki veya anatomik pozisyonda iken dış rotasyondaki omuzun elevasyonu ile kritik zonun korakoakromiyal bağ veya akromiyonun ön 1/3lük kısmının altında kalarak zarar gördüğünü öne sürmüştür. ${ }^{[9]}$

Neer ayrıca $80^{\circ}$ civarında abduksiyon esnasında supraspinatus tendonunun kritik zonunun akromiyoklavikular eklemin altından geçtiğini ve kolun baş 


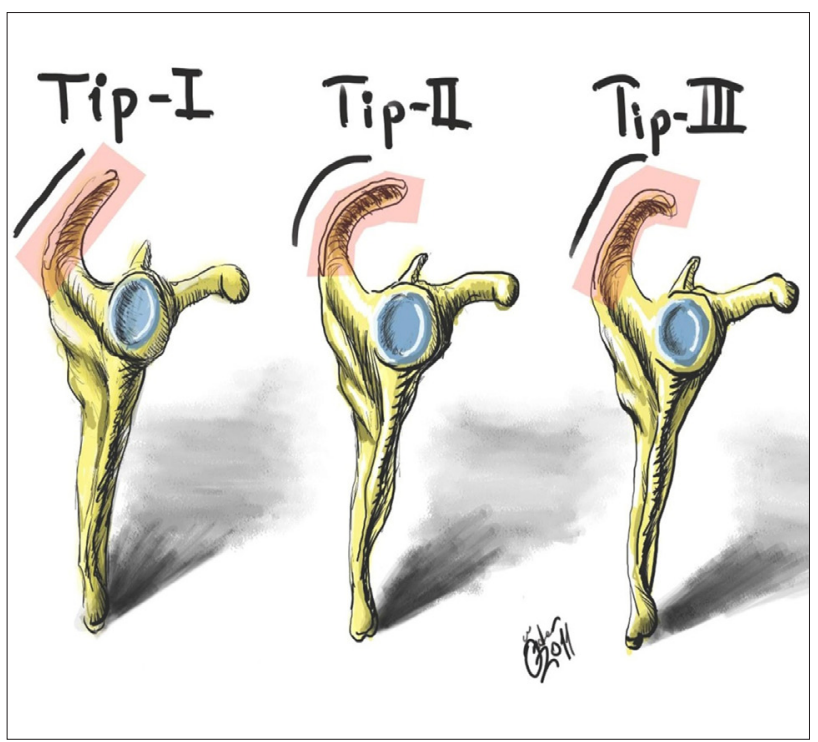

Şekil 3. Akromiyon tiplendirmesi.

üzerine elevasyonu ile bu alana akromiyal osteofitler tarafından bası uygulanabileceğini ifade etmiştir. ${ }^{[9]}$

1997 yılında Blevins ve ark.'nın ${ }^{[10]}$ yaptığı çalışma sonuçları ise, kritik avasküler zon teorisinin aksine, tendon beslenmesinin farklı olduğu bir alan bulamamıştır.

Morrison ve Bigliani'nin ${ }^{[11]}$ yaptıkları morfolojik çalısmada, akromiyon seklindeki değişikliklerin yırtıklarla olan ilişkisi gösterilmiştir. Bu çalışmada Tip I (düz), Tip II (eğri), ve Tip III (çengel) olmak üzere üç akromiyon şekli tanımlanmıştır (Şekil 3). Ortalama yaşı 74 olan 71 kadavranın 140 omzu incelenmiş; omuzların \%33'ünde tam kat yırtık olduğu görülmüş; yırtığı olan omuzların \%73'ünde Tip III, \%24'ünde Tip II, \%3'ünde Tip I akromiyon olduğu belirlenmiştir. ${ }^{[11]}$ Öte yandan, Yazıcı ve ark.[12] yenidoğan kadavralarında yaptıkları çalışmada, Tip II ve Tip III akromiyonların gelişimsel olmaktan çok, edinsel olabileceklerini ileri sürmüşlerdir.

RKY, baskın taraftaki kolda, baskın olmayana göre daha çok semptomatiktir. Semptomatik olan yırtığa baskın olmayan kolda da \%36 oranında yırtık eşlik edebileceği ortaya konulmuştur. US görüntüleme kullanımının yaygınlaşmasıyla bu oran 60 yaş üstünde $\% 50$ 'lere çıkmaktadır. ${ }^{[13]}$

Rotator manşet bütünlüğü üzerinde olumsuz etkisi bulunan bir başka parametre de sigaradır. Baumgarten ve ark.'nın ${ }^{[14]}$ yaptıkları çalışma sonucunda, doz ve zamana bağlı sigara içimi ile manşet yırtıkları arasında güçlü bir bağ ortaya konulmuştur. Yapılan bazı hayvan modeli deneylerinde de nikotinin tendon iyileşmesini geciktirici etkileri ortaya çıkmıştır. ${ }^{[15]}$
RKY'nin patofizyolojisinde dış faktörler de rol oynamaktadır. Yapılan çalışmalar supraspinatus tendon yırtığı sıklığının yaşla arttığını göstermiştir. ${ }^{[10,13]}$ Histolojik olarak da yaş arttıkça tendon yapışma yerinde hücresellikte ve damarlanmada azalma ve fibrokıkırdak doku kaybının artması söz konusudur. Hashimato'nun ${ }^{[16]}$ yakın zamanlı bir çalışmasında RKY'de yedi dış faktörden söz etmektedir:

1- Kolajen liflerin incelmesi ve dezoryantasyonu

2- Miksoid dejenerasyon

3- Hyalin dejenerasyon

4- Vasküler proliferasyon

5- Yağlı infiltrasyon

6- Kondroid metaplazi

\section{7- İntratendinöz kalsifikasyon}

Bu değişikliklerden, yağlı infiltrasyon ve vasküler proliferasyon, bursal tarafta görülürken, diğer histolojik değişiklikler eklem yüzeyi tarafında görülmektedir. ${ }^{[16]}$

Bir başka çalışmada ise RKY'nin uç kısımlarına komşu avasküler bağ dokuda SMA (Smooth Muscle Actin) miktarı artmış bulunmuştur. ${ }^{[17]} \mathrm{SMA}$ in vitro ortamda kollajen-glikozaminoglikan bileşkelerinin kasılmasını sağlar. İn vivo olarak da bu eylem, manşetin yırtık uçlarının kontrakte kalmasına neden olarak, birincil iyileşmeyi geciktirici etkiye sahip olabilir. ${ }^{[17]}$

Kişinin kollajen kalitesi de yırtık oluşumunda önemli bir faktördür. Sağlıklı bir supraspinatus tendon yapısında öncelikle Tip I kollajen lifler bulunmakta; tendon yapışma yerinde ise, kuvvete daha dayanıklı olan Tip II lifler ön plana çıkmaktadır. Yaralanan rotator manşette, Tip II liflerin yerini daha az dayanıklı Tip III liflere bıraktığı görülmüştür. ${ }^{[18]}$

\section{GÖRÜNTÜLEME}

Masif yırtıklarda, gerek tanı koyma gerekse cerrahi yöntem seçimi için, görüntüleme yöntemleri büyük önem taşımaktadır. Azalmış akromiyohumeral aralık, masif manşet yırtıklarına neden olabilir. MR görüntüleme ve US, RKY'yi görüntülemede en çok kullanılan iki yöntemdir. US, duyarıılık ve özgüllüğü tetkiki yapan kişiye bağımlı olmakla birlikte, dinamik bir testtir ve ağrıyı ortaya çıkaran manevralar esnasında omuzu görüntüleme olanağı sağlar. ${ }^{[19]}$ Ayrıca proksimal humerus kırıklarında kullanılan fiksasyon implantları veya omuz protezlerinde metalik artefakt kaynaklı görüntü distorsiyonunu engellemek için MR veya bilgisayarlı tomografi yerine US tercih edilmelidir. Ultrasonografik görüntüleme, eklem içi patolojileri ve kompleks yırtık paternlerini MR kadar iyi tanımlayamaz. ${ }^{20]}$ 
Yakın zamanlı çalışmalarda, RKY tanısı koymada, MR'nin \%100 özgüllüğü olduğu, yırtık boyutunu, retraksiyonu ve kasın yağlı infiltrasyonunu en doğru şekilde ölçme olanağı sağladığı ortaya konulmuştur. ${ }^{[21]}$

\section{TEDAVi}

Cerrahi dışı tedavi yöntemlerinin masif RKY'nin tedavisindeki önemi tartışmalıdır. Aktivite modifikasyonu, oral steroid olmayan ağrı kesici ilaçlar ve subakromial kortikosteroid enfeksiyonları ile semptomların başarıyla giderilebildiği bildirilmiştir. ${ }^{[22]}$ Fizik tedavi de kasların tekrardan eğitilmesi, kas ko-kontraksiyonunun koordinasyonu, skapula çevresi kasların güçlendirilmesi, hareket açıkığının korunması ve propriyosepsiyonun geliştirilmesi amaçları ile RKY tedavisinin önemli bir parçasını oluşturur. ${ }^{[8]}$

Masif RKY tedavisinde, cerrahi olarak çok geniş bir yelpazede seçenekler bulunmaktadır. Bunlar arasında açık veya artroskopik debridman ve akromiyoplasti, rotator manşet onarımı, tendon transferleri ile rotator manşet rekonstrüksiyonu, glenohumeral artrodez ve omuz artroplastisi sayılabilir.

Görece daha az hareketli olan, kolunu aktif olarak baş üzerine kaldırabilen ve dış rotasyon yaptırabilen hastalar yalnızca debridmandan yarar görebilirler. ${ }^{[22]}$ Bunun için, deltoid orijinin koruyan, daha pratik ve rehabilitasyon süresi daha kısa olan artroskopik teknik önerilmektedir. ${ }^{[23]}$

Rotator manşet onarımında amaç, korakoakromiyal arka zarar vermeden, rotator manşet tendonlarını proksimal humerusa onarmak ve subakromiyal alanı dekomprese etmektir. Yırtığın onarılabilirliği genel olarak yırtığın kronikliğine ve büyüklügüüne bağlıdır. Onarım için artroskopinin veya açık cerrahinin birbirine üstünlüğünü ispatlayan güçlü kanıtlar bulunmamaktadır. ${ }^{[24]}$

Bizim tercih ettiğimiz yöntem mini insizyon ve artroskopik destekle orta hatta kaçan dejenere olmuş suprspinatusu gevşetip, omuz eklemine çekmek ve tamir etmektir. Bu yöntemde, standart portallerden girilerek artroskopik subakromial dekompresyonu tamamlanır; takiben transdeltoid yaklaşık $4 \mathrm{~cm}$ 'lik insizyon ile yırtık bölgesine ulaşılır (Şekil 4). Supraskapular çentiğe doğru diseksiyon ilerlenerek supraspinatus tendonu bulunur ve posterior portalden illüminasyon yapılırken yapışıklıklar gevşetilir. Ana hedefimiz, supraskapular sinire ulaşmamak olmalıdır. Omuz $90^{\circ}$ abduksiyonda ve nötral rotasyondayken tendon iki adet çapa dikişi ile tek sıra tüberkülum majusa dikilir. Onarım bölgesinin üzerine örgü tarzında hyaluronik asit implantı yerleştirilerek girişim tamamlanır. Abduksiyon slinginde omuza erken hareket başlatılarak, üç hafta tamir uyguladığımız alan korunur. Daha sonra, belli sürelerde rehabilitasyona devam edilir. Altıncı haftada hasta serbest bırakıldıktan sonra, ortalama 3-4 ay içinde tam hareket elde edilir (Şekil 5).

Rotator manşet rekonstrüksiyonunda, rotator manşeti oluşturan ve diğer kas ve tendonların transferleri için çeşitli greftler veya sentetik malzemeler kullanılabilir. Subskapularis, supraspinatus ve latissimus dorsi daha sıklıkla tercih edilirken, teres minor, deltoid ve trapezius transferleri daha az kullanılmaktadır. ${ }^{25-28]}$ Greftlerle ve sentetik malzemelerle rotator manşet rekonstrüksiyonu ile ilgili deneyim daha kısıtlıdır ${ }^{[29,30]}$ ve genel olarak RKY'ye rotator manşet kas atrofisi de eşlik ettiği için, bu malzemelerin kullanımı, işlevlerin geri kazanılması için yeterli olamamaktadır.

Eklem yüzeylerinin rotator manşet rekonstrüksiyonuna izin vermeyecek kadar bozulduğu, korakoakromiyal arkın bozukluğuna bağı olarak omzun ağrılı antero-superior dislokasyonunun geliştiği kronik RKY hastalarında, kuvvetli ve stabil bir omuz kuşağı sağlanması amacıyla, glenohumeral artrodez bir tedavi seçeneği olarak gündeme gelebilir. ${ }^{[22]}$

Sonuç olarak, masif RKY'nin tam onarımı bazı hastalarda mümkün iken, diğerlerinde kısmi onarımla yetinilmektedir. Genç ve aktif hastalarda, işlevsel onarım amacıyla rotator manşet rekonstrüksiyonları önem arz eder. Omuz elevasyon ve dış rotasyonu kısıtlı olup deltoid gücü yerinde olan hastalarda, rekonstrüksiyon için latissimus dorsi tercih edilmelidir. ${ }^{[22]}$ Diğer rekonstrüksiyon seçeneklerinin yararları tartışmalı olup, debridmana üstünlükleri tam olarak kanıtlanamamıştır. ${ }^{[22]}$

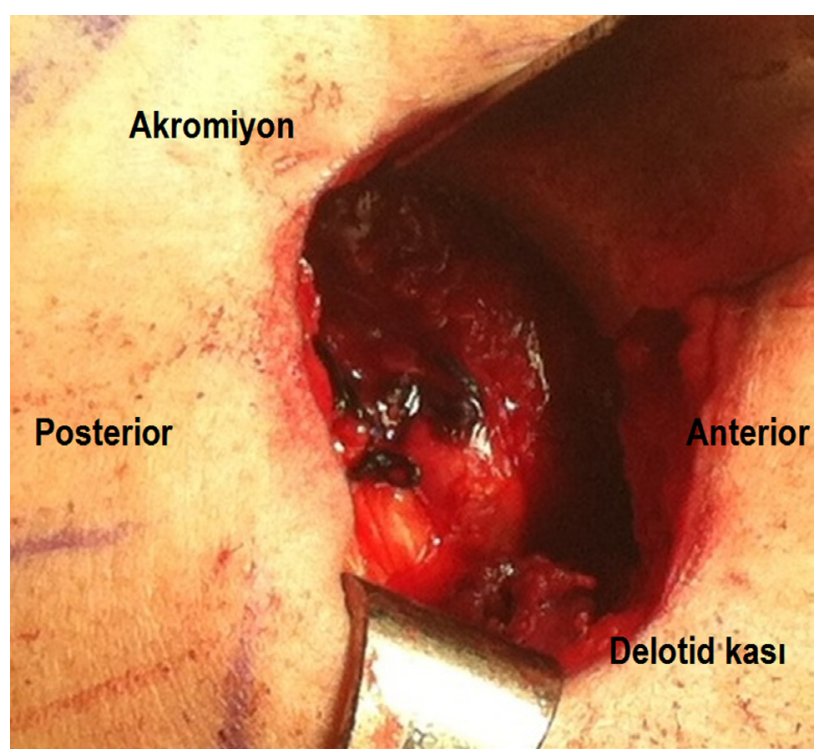

Şekil 4. Masif supraspinatus yırtığı tamirinde mini insizyon ile artroskopik yaklaşımın ameliyat sırasındaki görünümü. 

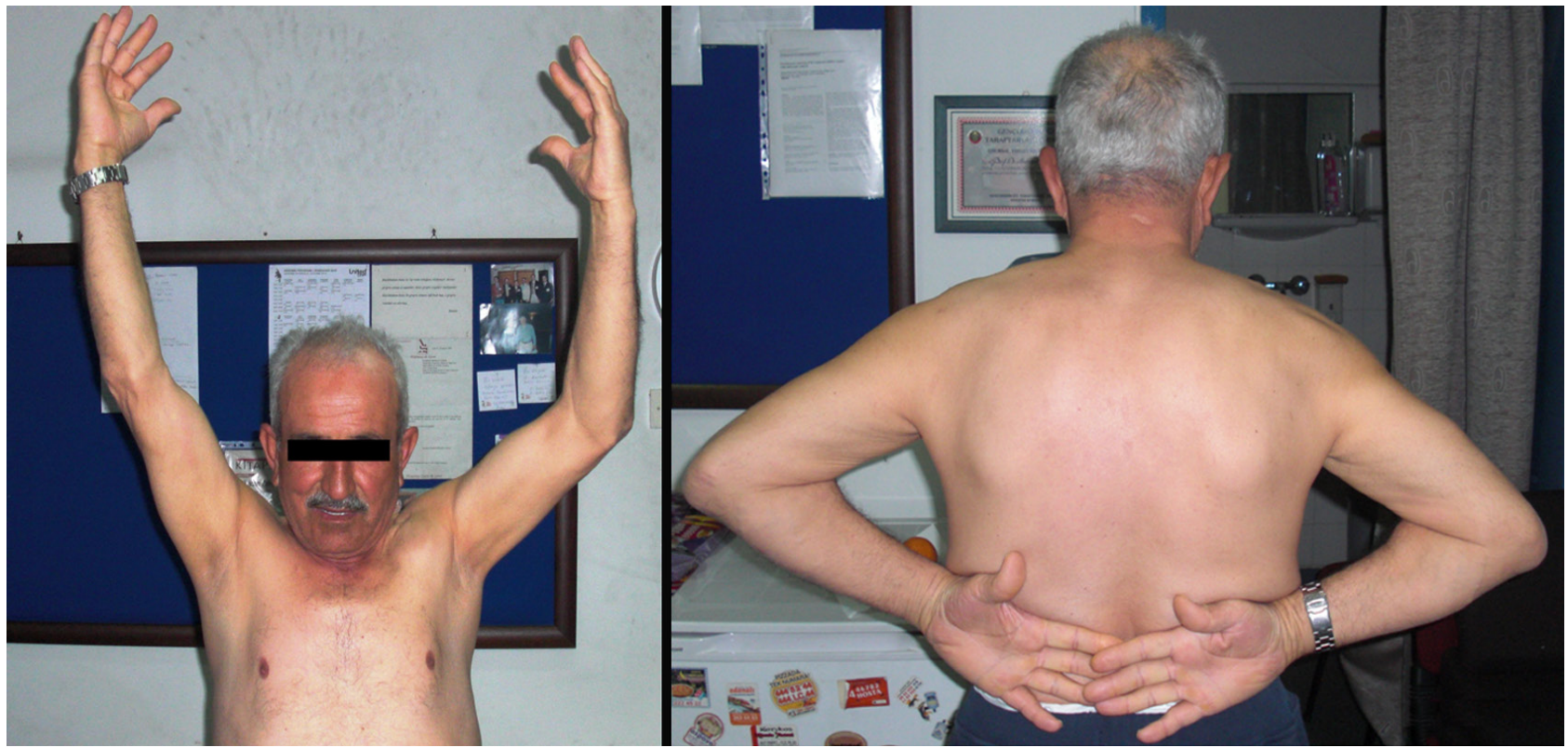

Şekil 5. Cerrahi sonrası dördüncü ay kontrolü.

Daha yaşı, inaktif ve özellikle ek sorunları bulunanlarda ise, tedavinin amacı ağrının giderilmesi olmalıdır. Bu konuda son yıllarda 'balon tekniği' olarak adlandırılan biyo-bozunur polimerlerin "spacer" olarak kullanımı, düşük-riskli ve basit bir yöntem olarak dikkat çekmektedir.[31,32]

\section{TEŞEKKÜR}

Çalışmamıza yaptıkları bilimsel katkılardan dolayı Dr. Ö. A. Atay, Dr. G. Dönmez ve Dr. FzT. D. Kaya'ya, görsellerin çizimlerinden dolayı ise Dr. Ö. Külekçi'ye teşekkür ederiz.

\section{KAYNAKLAR}

1. Cofield RH. Rotator cuff disease of the shoulder. J Bone Joint Surg Am 1985;67(6):974-9.

2. Gerber C, Fuchs B, Hodler J. The results of repair of massive tears of the rotator cuff. J Bone Joint Surg Am 2000;82(4):505-15.

3. Tauro JC. Stiffness and rotator cuff tears: incidence, arthroscopic findings, and treatment results. Arthroscopy 2006;22(6):581-6.

4. Burkhart SS. Arthroscopic treatment of massive rotator cuff tears. Clinical results and biomechanical rationale. Clin Orthop Relat Res 1991;(267):45-56.

5. Bedi A, Dines J, Warren RF, Dines DM. Massive tears of the rotator cuff. J Bone Joint Surg Am 2010;92(9):1894-908. CrossRef

6. Warner JJ, Gerber C. The Rotator Cuff: Current Concepts and Complex Problems. In: lannotti JP, Rosemont IL, editors. Treatment of massive rotator cuff tears: postero-superior and anterior-superior. American Academy of Orthopaedic Surgeons; 1998. p. 59-94.
7. Bölükbaşı S, Kanatlı U. Rotator Manşet Hastalıklarında tanı ve tedavi algoritması. TOTBID Dergisi 2003;2(1-2):1-16.

8. Neri BR, Chan KW, Kwon YW. Management of massive and irreparable rotator cuff tears. J Shoulder Elbow Surg 2009;18(5):808-18. CrossRef

9. Neer CS 2nd. Anterior acromioplasty for the chronic impingement syndrome in the shoulder: a preliminary report. J Bone Joint Surg Am 1972;54(1):41-50.

10. Blevins FT, Djurasovic M, Flatow EL, Vogel KG. Biology of the rotator cuff tendon. Orthop Clin North Am 1997;28(1):1-16.

11. Morrison DS, Bigliani L. The clinical significance of variations in acromial morphology. Orthop Trans 1987;11:234.

12. Yazici M, Kopuz C, Gülman B. Morphologic variants of acromion in neonatal cadavers. J Pediatr Orthop 1995;15(5):644-7.

13. Yamaguchi K, Ditsios K, Middleton WD, Hildebolt CF, Galatz LM, Teefey SA. The demographic and morphological features of rotator cuff disease. A comparison of asymptomatic and symptomatic shoulders. J Bone Joint Surg Am 2006;88(8):1699-704.

14. Baumgarten KM, Gerlach D, Galatz LM, Teefey SA, Middleton WD, Ditsios K, et al. Cigarette smoking increases the risk for rotator cuff tears. Clin Orthop Relat Res 2010;468(6):153441. CrossRef

15. Galatz LM, Silva MJ, Rothermich SY, Zaegel MA, Havlioglu $\mathrm{N}$, Thomopoulos S. Nicotine delays tendon-to-bone healing in a rat shoulder model. J Bone Joint Surg Am 2006;88(9):2027-34.

16. Hashimoto T, Nobuhara K, Hamada T. Pathologic evidence of degeneration as a primary cause of rotator cuff tear. Clin Orthop Relat Res 2003;(415):111-20.

17. Premdas J, Tang JB, Warner JP, Murray MM, Spector M. The presence of smooth muscle actin in fibroblasts in the torn human rotator cuff. J Orthop Res 2001;19(2):221-8. 
18. Longo UG, Franceschi F, Ruzzini L, Rabitti C, Morini S, Maffulli N, Denaro V. Histopathology of the supraspinatus tendon in rotator cuff tears. Am J Sports Med 2008;36(3):533-8.

19. Teefey SA, Hasan SA, Middleton WD, Patel M, Wright RW, Yamaguchi K. Ultrasonography of the rotator cuff. A comparison of ultrasonographic and arthroscopic findings in one hundred consecutive cases. J Bone Joint Surg Am 2000;82(4):498-504.

20. Teefey SA, Rubin DA, Middleton WD, Hildebolt CF, Leibold RA, Yamaguchi K. Detection and quantification of rotator cuff tears. Comparison of ultrasonographic, magnetic resonance imaging, and arthroscopic findings in seventy-one consecutive cases. J Bone Joint Surg Am 2004;86-A(4):708-16.

21. Harryman DT 2nd, Hettrich CM, Smith KL, Campbell B, Sidles JA, Matsen FA 3rd. A prospective multipractice investigation of patients with full-thickness rotator cuff tears: the importance of comorbidities, practice, and other covariables on self-assessed shoulder function and health status. J Bone Joint Surg Am 2003;85-A(4):690-6.

22. Green $A$. Chronic massive rotator cuff tears: evaluation and management. J Am Acad Orthop Surg 2003;11(5):321-31.

23. Gartsman GM. Massive, irreparable tears of the rotator cuff. Results of operative debridement and subacromial decompression. J Bone Joint Surg Am 1997;79(5):715-21.

24. Gerber C, Wirth SH, Farshad M. Treatment options for massive rotator cuff tears. J Shoulder Elbow Surg 2011;20(2 Suppl):S20-9. CrossRef
25. Cofield RH. Subscapular muscle transposition for repair of chronic rotator cuff tears. Surg Gynecol Obstet 1982;154(5):667-72.

26. Debeyre J, Patie D, Elmelik E. Repair of ruptures of the rotator cuff of the shoulder. J Bone Joint Surg Br 1965;47:36-42.

27. Dierickx C, Vanhoof $\mathrm{H}$. Massive rotator cuff tears treated by a deltoid muscular inlay flap. Acta Orthop Belg 1994;60(1):94-100.

28. Gerber C. Latissimus dorsi transfer for the treatment of irreparable tears of the rotator cuff. Clin Orthop Relat Res 1992;(275):152-60.

29. NeviaserJS, Neviaser RJ, NeviaserTJ. The repair of chronic massive ruptures of the rotator cuff of the shoulder by use of a freezedried rotator cuff. J Bone Joint Surg Am 1978;60(5):681-4.

30. Ozaki J, Fujimoto S, Masuhara K, Tamai S, Yoshimoto S. Reconstruction of chronic massive rotator cuff tears with synthetic materials. Clin Orthop Relat Res 1986;(202):173-83.

31. Kilinc AS, Ebrahimzadeh $\mathrm{MH}$, Lafosse L. Subacromial internal spacer for rotator cuff tendon repair: "the balloon technique". Arthroscopy 2009;25(8):921-4. CrossRef

32. Senekovic V, Poberaj B, Kovacic L, Mikek M, Adar E, Dekel A. Prospective clinical study of a novel biodegradable subacromial spacer in treatment of massive irreparable rotator cuff tears. Eur J Orthop Surg Traumatol 2013;23(3):311-6. CrossRef 